\title{
Vermeidung von Stichverletzungen
}

\author{
Wie Sie sich bei der Entsorgung von Einmal-Biopsiepistolen vor Stichverletzungen schützen, er- \\ fahren Sie in folgendem Tipp.
}

Blutentnahme-Nadeln und Venenverweilkanülen sind heute mit SicherheitsSchnappverschlüsen zur Vermeidung von Stichverletzungen versehen und werden in einem speziellen, schlagfesten, undurchlässigen Gefäß, dem „Spritzen-Abwurf“, entsorgt. Bei Einmal-Biopsiepistolen dagegen entsteht häufig ein Problem: Sie passen nicht in den Abwurfbehälter und ein Sicherheitsverschluss ist nicht vorhanden. Das Wiedereinführen der Nadel in die im Auslieferungszustand vorhandene Schutzhülle birgt das Risiko einer Verletzung mit der nach Gebrauch kontaminierten Nadelspitze. Dieses Verfahren ist darüber hinaus laut Unfallverhütungsvorschriften der BG untersagt.

Hier hat sich in unserer Hand eine einfache Maßnahme bei den von uns favorisierten Einmal-Biopsienadeln bewährt: Die Nadel wird umgebogen und in die Auslassöffnung der Nadel weg von der umbiegenden Hand eingesteckt ( $\triangle$ Abb. 1). Die Biopsiepistole kann nun im Müll ohne Gefährdung für Transport- oder Reinigungspersonal entsorgt werden.

\section{PD Dr. Andreas Wiedemann}

\section{Korrespondenz:}

PD Dr. Andreas Wiedemann

Urologische Klinik

Evangelisches Krankenhaus

im Diakoniewerk Ruhr gGmbH

Lehrstuhl für Geriatrie

der Universität Witten / Herdecke

Pferdebachstr. 27

58455 Witten

Tel.: 02 302/175-2521

awiedemann@diakonie-ruhr.de

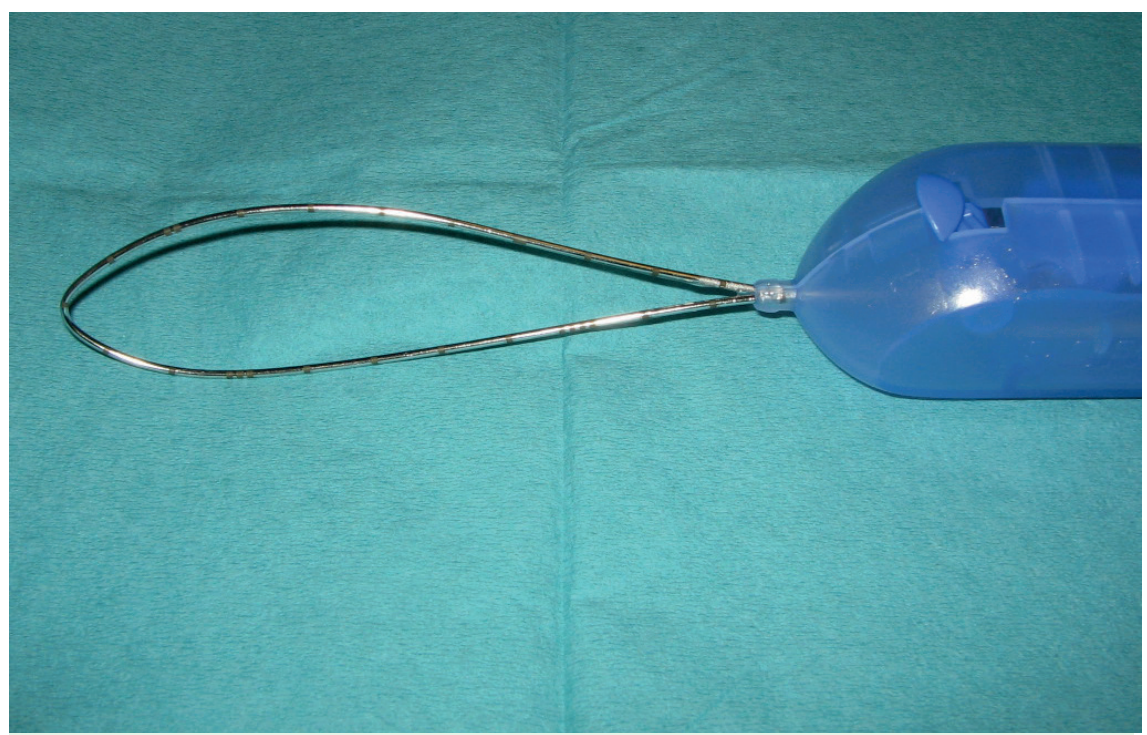

Abb.1 Die Nadel der Einmal-Biopsiepistole wird umgebogen und in die Auslassöffnung eingesteckt. Weder die umbiegende noch die die Pistole haltende Hand sind gefährdet. Die Pistole kann nun im Abfall entsorgt werden. 